\title{
The Influence of Intrafamilial Power on Maternal Health Care in Mali: Perspectives of Women, Men And Mothers-in-Law
}

By Darcy White, Michelle Dynes, Marcie Rubardt, Koman Sissoko and Rob Stephenson

Darcy White is public health program associate, and Rob Stephenson is associate professorboth in the Hubert Department of Global Health, Rollins School of Public Health, Emory University, Atlanta, GA, USA. Michelle Dynes is a former doctoral student, Nell Hodgson Woodruff School of Nursing, Emory University. Marcie Rubardt is senior technical advisor, CARE International, Atlanta. Koman Sissoko is project manager, CARE International, Bamako, Mali.

\begin{abstract}
CONTEXT: Evidence from diverse settings suggests that women often have limited control over their own reproductive health decisions. To increase uptake of preventive services and behaviors, it is important to understand how intrafamilial power dynamics and the attitudes of women, their husband and their mother-in-law are associated with maternal health practices.
\end{abstract}

METHODS: In 317 households in two rural districts of central Mali, women who had given birth in the previous year, their husband and their mother-in-law each completed a survey gauging their attitudes toward constructs of gender, power and health. Bivariate and multivariable logistic regression analyses were conducted to identify associations with four maternal health outcomes: antenatal care frequency, antenatal care timing, institutional delivery and postnatal care.

RESULTS: In multivariable analyses, the preferences and opinions of mothers-in-law were associated with the maternal health behaviors of their daughters-in-law. Women's own perceptions of their self-efficacy, the value of women in society and the quality of services at the local health facility were also independently associated with their preventive and health-seeking practices. Husbands' preferences and opinions were not associated with any outcome.

CONCLUSION: Interventions focusing on women or couples may be insufficient to advance women's reproductive health in patriarchal societies such as Mali. Future research and programmatic efforts need to address gender norms and consider the influence of other family members, such as mothers-in-law.

International Perspectives on Sexual and Reproductive Health, 2013, 39(2):58-68, doi: 10.1363/3905813

Despite decades of policies and programs aimed at improving reproductive health worldwide, high maternal morbidity and mortality persist in many resource-poor settings, particularly in Sub-Saharan Africa. ${ }^{1-3}$ The predominant approach to mitigating this problem has been to target the knowledge, attitudes and practices of women of reproductive age and to strengthen health service provision. Although educating and designing services for women is undoubtedly important, this focus assumes that women have control over their maternal health care decisions. Evidence from diverse settings, however, indicates that women often have only partial, if any, autonomy over their reproductive and sexual health. ${ }^{4-8}$ Not only do husbands have a significant influence on the behavior and actions of their wife, $7,9,10$ but other household members, especially mothers-in-law, also exert control over younger women.,11-13

Maternal morbidity and mortality are largely preventable through the provision of antenatal care, institutional delivery and timely postnatal care. ${ }^{8,14-17}$ Yet, in Sub-Saharan Africa, fewer than half of women receive the World Health Organization's recommended ${ }^{18}$ four or more antenatal care visits from a skilled provider, the majority deliver in the home and few receive postnatal care. ${ }^{17,19}$ Limited access to preventive and curative services, 8,20 inadequate health infrastructure and personnel, ${ }^{8,21,22}$ and inability to pay $^{8,21,22}$ have been recognized as formidable barriers to receipt of maternal health care. Recent research, however, indicates that supply side factors do not fully explain the variability in care-seeking practices, ${ }^{7,12,23}$ in some settings, substantial gaps in coverage remain even after adjustment for the availability of services.

Accordingly, researchers and program planners have begun to appreciate the complexity of contextual influences on maternal health practices, and have adopted an approach that recognizes that individual attitudes and behaviors are products of their social and cultural environments. ${ }^{24,25}$ Still, most studies have focused exclusively on women as the target population, and have aimed to understand and influence barriers and facilitators from their perspective. This narrow focus is incongruent with a sociocultural context in which women hold low status and are subject to the preferences and beliefs of their husband and elder relatives. ${ }^{26-28}$

Interpersonal power, however, has proven difficult to measure, such that power dynamics within a household and how they influence decisions on maternal health are not fully understood. ${ }^{6,29-31}$ To address this gap, we explored the link between household power dynamics and the maternal health behaviors of married women in rural Mali. Specifically, this article examines the relative influence of the preferences and beliefs of women, their hus- 
band and their mother-in-law on the frequency of women's antenatal care visits, antenatal care timing, place of delivery and receipt of postnatal care. Our findings contribute to the understanding of the influence of interpersonal and societal factors on maternal health behaviors, thereby informing the design of strategic programs and policies to improve the health and rights of women in resource-poor settings characterized by high maternal mortality.

\section{BACKGROUND}

Interpersonal power encompasses both "power to," which describes the ability of an individual to complete an action or behavior, and "power over," which refers to the ability to influence or control another person or to complete an act in the face of opposition. ${ }^{32}$ Both manifestations of power are influenced by social and normative prescriptions related to gender, ${ }^{32}$ and a growing body of research has shown that low female autonomy is associated with lower use of maternal health services. ${ }^{8,33-36}$

A challenge to research on power dynamics, however, is the lack of a clear operational definition of "power."6,31 To measure its effects, researchers have defined a core set of indicators and constructs that are believed to drive or reflect power dynamics. The most basic approach is to collect data on proxy measures, such as spousal disparities in age, education, employment or asset sharing ${ }^{30,31}$ characteristics thought to be associated with spousal inequity. More direct measures include scales for decisionmaking power, ${ }^{4,36-38}$ perceptions of gender equity ${ }^{10,39,40}$ and self-efficacy. ${ }^{41}$

Evidence suggests that power relations are shaped by constructs at the individual, interpersonal and societal levels, ${ }^{30,31}$ the effects of which cannot be fully understood in isolation. Therefore, researchers have increasingly begun to adopt a multidimensional approach, measuring power through various combinations of indicators, such as decision-making power, control over financial resources, freedom of movement, relationship control, attitudes toward or experience of intimate partner violence, and perceived self-efficacy. $6,12,34,42-45$

Although such studies have demonstrated that interpersonal power dynamics are associated with maternal health behavior, the previous approaches to measuring power have been limited in their ability to capture complex household relationships and fully explain patterns in health behaviors and outcomes. Notably, few studies have systematically assessed power from the perspectives of other key household members. Some analyses have included husbands, but have been limited in how they measured interpersonal power. A few, for example, have focused only on proxy indicators of power, ${ }^{9,30}$ whereas others have measured only one construct. ${ }^{10,46}$ In addition, studies have not linked data from male respondents to those of their female partners, ${ }^{10,33}$ which is important in understanding power dynamics at the household level. Several studies have included mothers-in-law, ${ }^{12,13,47}$ but they have not systematically analyzed mothers-in-law's power and influence to identify relevant constructs and their specific effects. In addition, most of these studies have been qualitative, ${ }^{12,13,47}$ although qualitative investigations are valuable, more quantitative studies with statistical modeling and analysis are needed.

\section{Malian Context}

Women in Mali are disadvantaged from a young age Educational opportunities are limited, ${ }^{48}$ more than $90 \%$ of females experience genital cutting ${ }^{49}$ and arranged marriage is common. ${ }^{28}$ After marriage, women go to live with their husband's family, where men have legally recognized authority over them. ${ }^{4,28,50}$ As of 2006 , nearly $40 \%$ of marriages in Mali were polygamous. ${ }^{51}$

Mali has one of the world's highest total fertility rates (6.6), yet use of modern maternal health services is low, according to the 2006 Demographic and Health Survey (DHS).$^{51}$ Seventy percent of women reported receipt of at least one antenatal care visit during their most recent pregnancy, yet only $35 \%$ reported four or more visits, and only $30 \%$ had had their initial visit within the first trimester, as recommended by the World Health Organization. ${ }^{18}$ Fewer than half (45\%) of women who gave birth in the five years preceding the survey had delivered in a health facility, and only $22 \%$ had received postnatal care within 48 hours after delivery. Reflective of these inadequate levels of preventive care, coupled with limited access to treatment for complications, the maternal mortality ratio for 2000-2006 was 464 deaths per 100,000 live births and the infant mortality rate for 2001-2006 was 96 deaths per 1,000 live births. Other estimates put those figures as high as 830 and 103 , respectively. ${ }^{48}$

\section{METHODS \\ Data and Setting}

Data for this analysis were drawn from the Projet Espoir Baseline Survey (PEBS), which was conducted between June and July 2011 in Bandiagara and Bankass, two rural districts of central Mali's Mopti region. This article contributes to the project's larger goal of identifying and addressing underlying social determinants of poor maternal health in rural Mali. Ethical approval was obtained from the institutional review boards at Emory University and the Malian Ministry of Health.

The Mopti region is predominantly rural and agricultur$\mathrm{al}$, and has the lowest levels of education in the country. ${ }^{51}$ Although men and women in the region have roughly equal educational profiles overall, among younger cohorts, educational attainment is improving at a higher rate for males than for females. ${ }^{51}$ Gender disparities are also evident in the mean age at marriage, which is 17 among women and 27 among men. On average, women in Mopti have their first birth at age 19, and the total fertility rate for the region is 6.3. Although two-thirds of women in Mopti received at least one antenatal care visit for their most recent pregnancy, only 30\% delivered in a health facility, and only 15\% received postnatal care within 48 hours after giving birth. 
The study's sample comprised 544 randomly selected households-275 in Bandiagara and 269 in Bankass. To be included in the study, a household had to contain a woman who had given birth in the previous 12 months (the index woman), and both she and her husband had to be present to be interviewed. Mothers-in-law were also interviewed when possible, to capture a range of opinions and perspectives within a household. Parallel questionnaires were administered separately to each household member. Surveys included questions about background information and social and demographic characteristics, as well as items regarding maternal health, gender and intrafamilial power. The questionnaire administered to index women also covered current contraceptive use, birth history, maternal health practices and care-seeking behavior during the most recent pregnancy.

From the 544 households sampled, 544 women, 527 husbands and 356 mothers-in-law completed interviews. Ten households were dropped because survey responses indicated that the woman was not currently married or had not given birth in the past 12 months, which yielded a sample of 534 households with surveys from 534 women, 519 husbands, and 353 mothers-in-law.

\section{Variables}

- Outcome variables. We created four dichotomous outcome variables as indicators of index women's maternal health behavior during their last pregnancy: receipt of four or more antenatal care visits, receipt of the first antenatal care visit within the first trimester of pregnancy, delivery at a health facility and receipt of an examination from a skilled provider within 48 hours after delivery. Skilled providers were operationally defined as nurses, midwives, physicians and health or clinical officers.

- Primary covariates. The primary covariates were scaled measures based on eight sets of items assessing respondents' attitudes toward or perceptions of traditional practices in pregnancy and childbirth, the value of women, marital conduct and responsibilities, local health facilities, the index woman's efficacy, household trust and respect, overall household power and decision-making power. For each statement or question, respondents were prompted to indicate their opinion or perceived level of influence by pointing to the appropriate spot on a picture of a 10runged ladder, with the bottom rung indicating total disagreement or no influence and the top rung representing total agreement or total influence. The items were administered to women, husbands and mothers-in-law, except for those concerning trust and respect, which were asked only of index women.

Traditional pregnancy and childbirth practices were measured by respondents' level of agreement with five statements, such as "a woman must obey her husband during pregnancy to make sure she has an easy delivery" and "a woman should not bathe after sunset." The perceived value of women was assessed by a set of six items, including "women cannot make household decisions alone" and "a woman should not start her own economic activities without the consent of her in-laws." Opinions regarding marital conduct and responsibilities were measured by agreement with five statements, such as "it's a woman's responsibility to avoid getting pregnant" and "a man can hit his wife if she refuses to have sex with him." To assess attitudes toward the local health facility (referred to as the CS-COM), the surveys included seven statements, such as "the CS-COM provides high-quality services." The index woman's efficacy was measured by respondents' answers to three questions about whether, if she wanted to, she could decide to have only two children, deliver her baby in a health facility or go to a health center alone. Overall household power was measured by questions asking respondents how much power they perceived each member of the household to have. Household decision-making power was measured by assessing how much influence respondents perceived specific household members to have on decisions about how many children to have, whether to circumcise a girl, where a woman should give birth, whether to seek modern health care during childbirth and whether to sell the family's animals. From this data on decision-making, we created a new set of scales for each respondent group, by subtracting the rating of the decision-making power of the index woman from that of the husband. Finally, index women responded to five items about household trust and respect, including "I feel that I am an important member of this family" and "I trust my mother-in-law to help me if I need help."

For household power, a single scale was created to indicate index women's view of the balance of power at the couple level by subtracting their perception of their own power from their perception of their husband's power. For example, if a woman perceived her power to be a four on the ladder and her husband's power to be a 10, her household power score would be a six; higher scores indicate greater power imbalances. Similar scales were not created for husbands and mothers-in-law, because it was not possible to identify which responses corresponded to the index women in polygamous households.

To reduce the data from each of the remaining sets of scale items to weighted indices representing the central constructs, we performed principal components analyses separately on responses from women, husbands and mothers-in-law using STATA version 12.0. Prior to principal components analyses, all scale items with reverse directionality in meaning to the rest of the items were reverse coded. We then conducted preliminary reliability analyses to identify items negatively correlated with the remainder of the items in their set. Items that were negatively correlated with the data for any of the three respondent groups were dropped from all analyses to ensure comparability in the scales across the sample. The final indices were created using the first factors (principal components) identified through orthogonal variance maximizing rotation. Items were assigned weights relative to their contribution to the variance of the first factor. 
The resulting measures are noninterval indices, for which higher scores indicate greater agreement with the construct or greater perceived power. We refrain from referring to values or units when describing the associations with these measures, as each index is comprised of information extracted from a set of interrelated variables to represent the domain of interest. (For index properties, see Appendix Table 1.)

-Additional variables. Control variables for women's ethnicity, age at marriage, parity and ability to decide whom they married were included in analyses, given those characteristics' documented associations with fertility and reproductive health outcomes. 3,31,32,36,52,53 In addition, research on polygamous unions suggests that a wife's rank influences her status and health, ${ }^{.54}$ thus, we created a marital status variable consisting of only wife, first wife in a polygamous union and subsequent wife in a polygamous union. Last, we included a measure of whether the woman ever had a child die within the first year of life, because this experience may influence subsequent maternal health practices.

Age, educational attainment and employment status are also related to both power and reproductive health. ${ }^{3,23,32,45,52}$ Yet, research on spousal power dynamics suggests that the relative difference in status between a husband and wife is more important than absolute measures. ${ }^{31}$ Therefore, we combined data on these three demographic indicators for women and for their husbands to create variables representing spousal differences. Because of the small number of households in which both the husband and wife were educated $(n=13)$, we created a single category to indicate equal education, which represents households in which both partners had some education and those in which both partners had no education. For consistency, we used the same categorization for patterns of employment.

\section{Analysis}

For our analysis, we restricted the sample to households in which the index woman, her husband and her mother-inlaw all completed surveys, which resulted in a final sample of 317 households. Compared with women from households with complete data, women from those in which the husband or mother-in-law was not present were more likely to have married later ( $p=.005$ ), to be older at the time of the survey $(p=.025)$ and to be in monogamous marriages $(\mathrm{p}<.001)$

We conducted bivariate logistic regression analyses to examine unadjusted associations between independent variables and each of the four dependent variables; an alpha of .10 was used as the level of significance. After we checked for collinearity, we included all independent variables found to be significant in bivariate analyses in multivariable logistic regression models. For each outcome measure, we started with a full model and then, one at a time, removed the variables with the highest nonsignificant adjusted p-values. After each removal, we examined the beta estimates of the remaining factors; if an adjusted beta coefficient changed by $10 \%$ or more, the dropped variable was reentered into the model to control for confounding. This process was repeated for each outcome until the most parsimonious model was reached. All analyses were conducted using STATA version 12.0.

TABLE 1. Percentage distribution of women and couples, by selected characteristics

Characteristic

WOMAN

Ethnicity

Dogon

Peulh

Other

Marital status

Only wife

First wife

Other wife $(\mathrm{N}=317)$

Age at first marriage

$\leq 15$

16-19

$\geq 20$

Don't know

81.1

10.1

8.8

Had a say in whom to marry

No

Yes

Parity

1

2-3

4-5

$\geq 6$
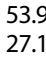

27.1
18.9

Child died by age 12 months

No

Yes

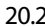

33.4

6.9

39.4

44.8

55.2

12.6

39.1

24.0

24.3

COUPLE

Age discrepancy

$-5-9$

$\geq 10$

Don't know

67.5

32.5

\section{Educational discrepancy}

Wife educated, husband not

Equal educational attainment

Husband educated, wife not

Difference in employment status

Wife works, husband does not

Equal employment status

Husband works, wife does not

28.1

27.1

44.8

MATERNAL HEALTH CARE $†$

Received four or more antenatal care visits

Yes

No

Received first antenatal visit within the first trimeste

Yes

No

Delivered in a health facility

Yes

No

Received postnatal care within $\mathbf{4 8}$ hours of delivery

Yes

No

Total

tIn reference to index woman's last pregnancy. Notes: Percentages may not add to 100.0 due to rounding. Age discrepancy is the wife's age subtracted from the husband's age. 


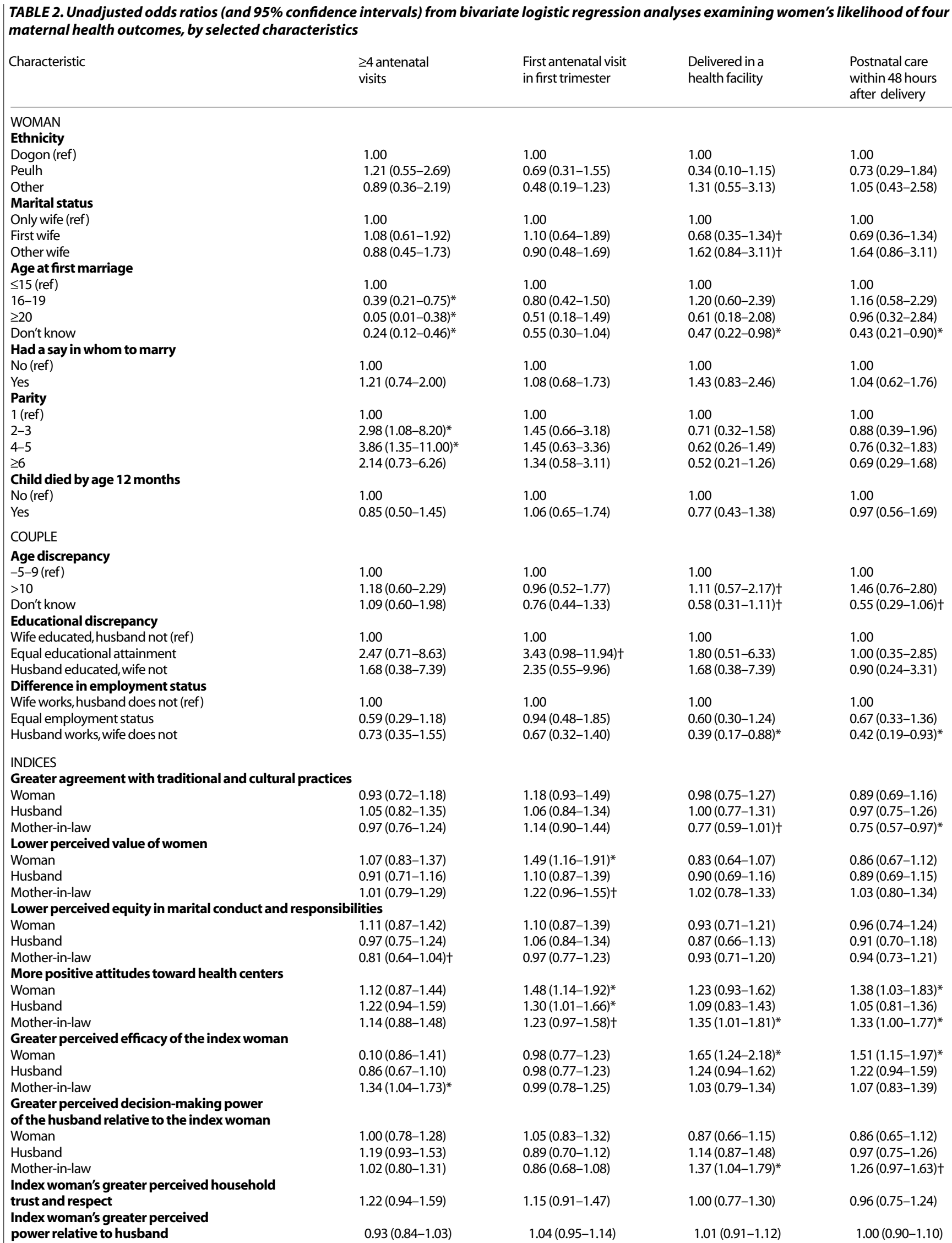

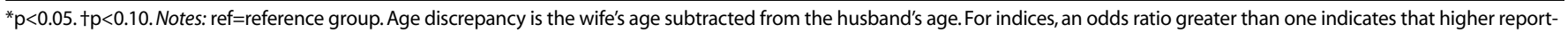

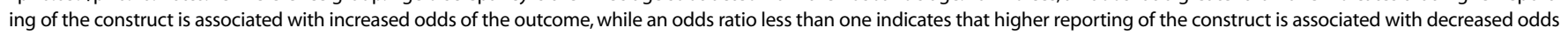
of the outcome. 


\section{RESULTS}

\section{Descriptive Statistics}

Fifty-four percent of index women reported being their husband's only wife, $27 \%$ were the first wife in a polygamous union, and 19\% were a subsequent wife in a polygamous union (Table 1, page 61). More than half of women reported marrying before the age of 20 (54\%) and a similar proportion reported having a say in whom they married (55\%). The vast majority (87\%) had already delivered one or more children at the time of their most recent birth; the average parity was 2.9 prior births per woman (not shown). One-third of women reported having experienced the death of a child before age 12 months.

The mean age of index women was 25.2 years, and the mean age of their husbands was 36.5 years (not shown); among the 175 couples in which both partners knew their age, husbands were an average of 10 years older. Educational attainment was low for both men and women, and for $83 \%$ of couples, both spouses had the same level of education. In contrast, husbands were more likely to be employed: In 33\% of couples, only the husband worked, whereas only the wife worked in 14\% of couples.

Women reported low levels of maternal health care for their most recent pregnancy. Only 27\% had received four or more antenatal care visits, 34\% had received their first antenatal visit within the first trimester, $22 \%$ had delivered in a health facility, and $24 \%$ had received postnatal care from a skilled provider within 48 hours after delivery.

\section{Frequency of Antenatal Care Visits}

Four variables were associated with antenatal care frequency at last pregnancy in unadjusted analyses: the index women's age at first marriage and parity, as well as mothers-in-law's views of appropriate marital conduct and of their daughter-in-law's efficacy (Table 2). In the adjusted analysis, all but the mothers-in-law's opinions regarding marital conduct and responsibility were significant (Table 3). Compared with women who first married at age 15 or earlier, those who married later or did not know their age at marriage had lower odds of having received four or more antenatal care visits (odds ratios, 0.1-0.4). The odds of receiving more frequent antenatal care increased with higher parity and peaked among women for whom the most recent birth was their fourth or fifth (5.2). Last, women's odds of having received four or more antenatal care visits were positively associated with their mother-inlaw's perceiving that they had greater efficacy (1.3).

\section{Timing of First Antenatal Care Visit}

Receipt of the first antenatal care visit within the first trimester was associated at the bivariate level with educational attainment, women's and mothers-in-law's perceptions of the value of women, and the attitudes of all three respondent groups toward health facilities (Table 2). In the full adjusted model, only the associations with educational attainment, women's perceptions of the value of women and their positive attitudes toward health facilities
TABLE 3. Adjusted odds ratios (and 95\% confidence intervals) from multivariable logistic regression examining women's likelihood of having received four or more antenatal visits for their last pregnancy, by selected characteristics

Characteristic

$\geq 4$ antenatal visits

Age at first marriage

$\leq 15$ (ref)

$16-19$

$\geq 20$

Don't know

1.00

$0.42(0.21-0.81)^{*}$

$0.05(0.01-0.38)^{*}$

$0.21(0.11-0.42)^{*}$

Parity

1 (ref) 1.00

2-3

3.31

$5.22(1.73-15.71)^{*}$

$\geq 6$

$2.63(0.85-8.15) \dagger$

Mother-in-law's greater perceived efficacy of the index woman $1.34(1.02-1.76)^{*}$

${ }^{*} p<0.05 .+p<0.10$. Notes: $r e f=$ reference group. For indices, an odds ratio greater than one indicates that higher reporting of the construct is associated with increased odds of the outcome, while an odds ratio less than one indicates that higher reporting of the construct is associated with decreased odds of the outcome.

remained significant (Table 4). Compared with women who were more educated than their husband, women educated at the same level as their husband had greater odds of having received early antenatal care (odds ratio, 4.1). Women whose responses reflected a lower perceived value of women in society also had greater odds of early antenatal care (1.5), as did women with scores indicating more positive attitudes toward health services (1.5).

\section{Institutional Delivery}

In the unadjusted analyses, delivering in an institution was associated with women's marital status and age at marriage, their age and employment discrepancy with their husband, and their perceived self-efficacy (Table 2). Institutional delivery was also associated with mothers-in-law's agreement with traditional practices, positive attitude toward the health facility and perception of the difference in decision-making power between their son and daughterin-law. In the adjusted model, only four factors remained independently associated with delivery in a health facility

TABLE 4. Adjusted odds ratios (and 95\% confidence intervals) from multivariable logistic regression examining women's likelihood of having received the first antenatal visit of their last pregnancy within the first trimester, by selected characteristics

Characteristic

First antenatal visit in first trimster

\section{Educational discrepancy}

Wife educated, husband not (ref)

Equal educational attainment

1.00

Husband educated, wife not

$4.10(1.15-14.62)^{*}$

$2.55(0.58-11.21)$

Lower perceived value of women

Woman

$1.45(1.12-1.89)^{*}$

Mother-in-law

$1.17(0.90-1.51)$

More positive attitudes toward health centers

Woman

$1.54(1.17-2.01)^{*}$

Husband

$1.17(0.90-1.52)$

${ }^{*} \mathrm{p}<0.05$. Notes: ref=reference group. For indices, an odds ratio greater than one indicates that higher reporting of the construct is associated with increased odds of the outcome, while an odds ratio less than one indicates that higher reporting of the construct is associated with decreased odds of the outcome. 
(Table 5). Compared with women who were the sole wage earner in their marriage, women whose husband was the sole wage earner had lower odds of having delivered in a health facility (odds ratio, 0.4). Having a mother-in-law whose index score indicated greater agreement with traditional and cultural practices surrounding pregnancy and childbirth was also negatively associated with institutional delivery (0.7). On the other hand, institutional delivery was positively associated with women's perceptions of their greater self-efficacy and with mothers-in-law's perception of the greater difference in decision-making power between their son and daughter-in-law (1.8 and 1.6, respectively).

\section{Postnatal Care}

Similar to the result for institutional delivery, the unadjusted odds of women's having received postnatal care within 48 hours of delivery were associated with women's age at marriage, difference in age from their husband, difference in employment from their husband and perceived self-efficacy (Table 2). In addition, women's and mothers-in-law's positive attitudes toward the health facility, and mothers-inlaw's agreement with traditional practices and perception of the difference in decision-making power between their son and daughter-in-law were associated with postnatal care at the bivariate level. Four of these associations remained significant in the adjusted model (Table 6). A mother-in-law's greater agreement with traditional practices was negatively associated with her daughter-in-law's receipt of postnatal care (odds ratio, 0.7). However, a mother-in-law's belief that her son had more decision-making power than his wife

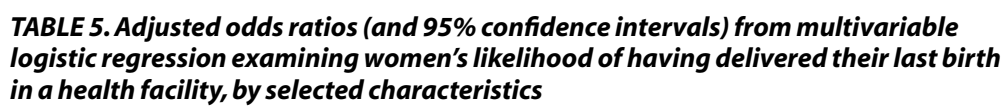

Characteristic

Delivered in a health facility

Age at first marriage

$\leq 15$ (ref)

$16-19$

$\geq 20$

Don't know

1.00

$1.13(0.53-2.41)$

$0.35(0.10-1.49)$

$0.50(0.22-1.11)+$

\section{Marital status}

Only wife (ref)

1.00

First wife

Other wife

$0.59(0.29-1.22)$

$1.41(0.68-2.94)$

\section{Difference in employment status}

Wife works, husband does not (ref)

1.00

Equal employment status

Husband works, wife does not

$0.66(0.30-1.47)$

$0.40(0.16-0.98)^{*}$

Mother-in-law's greater agreement with traditional

$0.70(0.52-0.94)^{*}$

and cultural practices

Woman's greater perceived self-efficacy

$1.82(1.31-2.54)^{*}$

Mother-in-law's greater perceived decision-making power of her son relative to her daughter-in-law

${ }^{*} \mathrm{p}<0.05 .+\mathrm{p}<0.10$. Notes: $r \mathrm{f}=$ reference group. For indices, an odds ratio greater than one indicates that higher reporting of the construct is associated with increased odds of the outcome, while an odds ratio less than one indicates that higher reporting of the construct is associated with decreased odds of the outcome. was positively associated with the outcome (1.4). Women's scores on the indices representing more positive attitudes toward local health services and greater perceived selfefficacy were also positively associated with their receipt of postnatal care (1.4 and 1.6, respectively).

\section{DISCUSSION}

In this study, we collected parallel data from women in rural Mali, their husbands and their mothers-in-law, which provide rich contextual insights into the layers of influence that shape maternal health in the region. Our results indicate that the relevant factors and constructs vary considerably across the four maternal health outcomes, though patterns in the associations hint at the underlying mechanisms and processes that drive power dynamics within a family.

In particular, our results point to the influential role of mothers-in-law in determining patterns of maternal health care. The negative associations between mothers-in-law's greater agreement with traditional practices and women's delivering in a health facility and their receiving postnatal care suggest that the decision to seek modern, institutional health care falls-at least in part-in the domain of the mother-in-law. Women's own opinions regarding traditional practices had no bearing on the care they received. Mothers-in-law who adhere to and believe in the efficacy of such practices may see institutional care as unnecessary or even detrimental, such that they discourage their daughters-in-law from seeking care from trained providers. In forming these beliefs and opinions, mothers-in-law may be drawing on their own maternal health care experiences; if they did not receive modern health care, they may be unlikely to view it as important for their daughters-in-law.

A mother-in-law's perception of the balance of decisionmaking power between her son and daughter-in-law was also found to be related to institutional delivery and receipt of postnatal care. In households where the mother-in-law reported that her son has more control than her daughterin-law over decisions such as where to give birth and how many children to have, the index woman had greater odds of having delivered in an institution and having received timely postnatal care. These results are unexpected and indicate the complexity of decision-making processes. One possible explanation is that mothers-in-law who to a greater extent consider fertility and childbirth to be men's decisions may be less likely to intervene and impose their own views. In contrast, mothers-in-law who perceive such issues to be more in women's domain may assert their dominance as the woman of higher status and insist on a more traditional delivery. This interpretation assumes that husbands are more accepting of modern, institutional health care than their mothers, however, and merits further investigation.

In addition, mothers-in-law's perception of their daughter- in-law's greater efficacy was positively associated with receipt of the recommended number of antenatal care visits and delivery at a health facility. A mother-in-law who 
supports and believes in the greater personal efficacy of her daughter-in-law may indicate more equitable gender norms in the household and greater trust and communication between the women. In turn, women's perception of their own greater self-efficacy was found to be positively associated with their delivering in an institution and receiving postnatal care. Other studies have also reported positive associations between self-efficacy and the adoption of preventive health behaviors. ${ }^{41,44}$ Promoting self-efficacy entails teaching skills and reducing perceived barriers: For example, programs that encourage participants to practice partner communication and to discuss and challenge problematic attitudes and norms have been shown to increase self-efficacy and promote behavior change. ${ }^{57}$ Furthermore, programs addressing these gender and power dynamics among women currently of reproductive age have the potential to shift attitudes and norms regarding roles and decisions in the household, thus improving the experiences of future generations of women.

A surprising finding was that women who had a lower opinion of the value of women had greater odds of receiving early antenatal care. In the pronatal context of Malian society, women who perceive the value of women to be low may be more likely to view successful childbearing as a woman's responsibility and an essential determinant of her social status. If antenatal care is perceived as a means of having a healthy birth, it is possible that, for these women, early care-seeking is viewed as integral to fulfilling their role as women. ${ }^{32}$ Further research exploring the link between maternal health behavior and women's perception of the value of women is needed to validate and better understand this unexpected association.

Women's attitudes toward their local health center also influenced their use of maternal health care. Although such attitudes are not necessarily indicative of power dynamics, the fact that women's opinions influenced service utilization, even after adjusting for all other factors, suggests that women had some control over their personal health care use. In recognition of this association, health centers should focus on improving the quality of services and on making women aware of the range and quality of services available to them. Investment in quality will require more than obtaining better equipment and stocking supplies; our scale was based on items addressing women's perceptions of how they are treated at the facilities, the overall service quality and the information provided. This is consistent with findings from a variety of settings that indicate that disrespect and abuse at health facilities influence health-seeking behavior. ${ }^{33,58-61}$

Together, our findings suggest a need for interventions targeting a range of stakeholders at multiple levels. Decisions regarding use of maternal health care seem not to be made solely at the individual or the dyadic level; the values and opinions of other family members, and the broader social and cultural context, appear to play an influential role. Informed by these results, CARE USA and CARE Mali have developed a package of interventions, including
TABLE 6. Adjusted odds ratios (and 95\% confidence intervals) from multivariable logistic regression examining women's likelihood of receiving postnatal care from a skilled provider within 48 hours after delivery, by selected characteristics

Characteristic

Postnatal care within

48 hours after delivery

Age at first marriage

$\leq 15$ (ref)

1.00

16-19

$\geq 20$

Don't know

$0.91(0.28-2.94)$

$0.51(0.20-1.28)$

\section{Age discrepancy}

$-5-9$ (ref)

$\geq 10$

1.00

Don't know

$1.32(0.65-2.67)$

$0.83(0.36-1.90)$

Difference in employment status

Wife works, husband does not (ref)

Equal employment status

Husband works, wife does not

Mother-in-law's greater agreement with traditional and cultural practices

Woman's more positive attitudes toward health centers

1.00

$0.83(0.38-1.82)$

$0.46(0.19-1.09) \dagger$

$0.71(0.53-0.94)^{*}$

$1.40(1.03-1.89)^{*}$

Greater perceived efficacy of the woman

Woman

Husband

$1.63(1.20-2.22)^{*}$

$1.18(0.87-1.61)$

Mother-in-law's perceived greater decision-making power of her son relative to her daughter-in-law

$1.40(1.03-1.90)^{*}$

${ }^{*} \mathrm{p}<0.05 .+\mathrm{p}<0.10$. Notes: $\mathrm{ref}=$ reference group. Age discrepency is the wife's age subtracted from the husband's age. For indices, an odds ratio greater than one indicates that higher reporting of the construct is associated with increased odds of the outcome, while an odds ratio less than one indicates that higher reporting of the construct is associated with decreased odds of the outcome.

couple counseling on prenatal care and birth planning; male-friendly services for prenatal care and delivery to encourage male engagement; and extended family meetings to involve other decision makers, such as mothers-in-law or brothers-in-law, in planning for pregnancy care and delivery. Community action groups have also been formed to reinforce the acceptability of shifting social norms and to increase community responsibility for the health of pregnant women. By intervening at multiple levels within the community, this combination of interventions aims to tackle the prevailing social and cultural norms that negatively influence maternal health behaviors and outcomes, complementing more traditional service-strengthening interventions in the health facilities.

\section{Limitations}

Our study had several limitations. Because of the study's cross-sectional design, we were unable to determine causality. All data were self-reported, which introduces possible recall and social desirability biases. Additionally, the households included in the analyses represent a subset of the original sample, which limits the generalizability of the results. However, because a primary focus of this study was to explore the influence of other family members, the restriction to households in which a mother-in-law completed the survey was necessary. Studies that allow for comparisons in power dynamics between households 
with and without a mother-in-law and that explore the influence of other household members would be useful to help clarify these patterns.

Because of sample size limitations-specifically, the small number of women in our sample who married at older ages-the association found between age at marriage and frequent antenatal visits should be interpreted with caution. This finding seems to contradict the understanding drawn from previous studies that higher age at marriage grants women more time to obtain education, ${ }^{32}$ which confers greater social support, negotiation skills and appreciation for the importance of reproductive health services. ${ }^{30,32}$

Also of note, our measure of postnatal care within 48 hours after delivery may not reflect purposive healthseeking. Women who delivered in an institution likely received-or assumed that they received-a postpartum checkup by default. Future studies should develop alternative measures of postnatal care that more accurately capture an element of agency in postpartum care seeking.

The small number of items related to each construct limited the internal consistency of the indices, as reflected by low Cronbach's alpha reliability coefficients. Subsequent studies should incorporate cognitive interviewing and indepth qualitative research to inform the development of scale items and definitions, identify more items for inclusion and systematically validate the scales to test that they truly capture relevant constructs. Finally, this exploratory analysis focused solely on individual and household variables. Thus, it did not control for community-level factors associated with reproductive health indicators in other studies, such as accessibility of health facilities, $, 15,62$ exposure to mass media, 9,36,45,52 average educational attainment in the community ${ }^{8,37}$ and community norms. ${ }^{37}$ Future research should assess the combined effects at all three levels.

\section{Conclusion}

Although Mali has a strongly patriarchal society, it seems that women-older women in particular-exert influence over maternal health decisions. In this analysis, husbands' perspectives and opinions did not emerge as independent predictors in any of the final models. Previous studies have reported that husbands' opinions and attitudes influence fertility and childbearing, 4,7,10,36,63 although few of these studies have measured multiple complex constructs of power, and fewer have considered the effects of mothersin-law and husbands together. Our results suggest that the influence of mothers-in-law may overshadow the role of men in maternal health decision making in some societies.

The slow progress in Sub-Saharan Africa toward the goal of reducing maternal morbidity and mortality suggests a need for programs and policies that recognize the influence of factors at the family, societal and cultural levels. Particularly in patriarchal societies with low gender equity, intrafamilial power dynamics need to be addressed. This study contributes to existing literature in finding that women in Mali do not have independent control over their own maternal health decisions; social norms, gender scripts and intrafamilial hierarchies impede preventive and health-seeking behaviors. However, experience has shown that neither gender constructs nor family dynamics are static. $^{31,64}$ Given the profound implications for health and rights, there is a critical need for well-designed, evidencebased interventions to achieve a more equitable balance of power within households and at the community level.

\section{REFERENCES}

1. Gribble J and Haffey J, Reproductive Health in Sub-Saharan Africa, Washington, DC: Population Reference Bureau, 2008.

2. World Health Organization (WHO), Achieving Millennium Development Goal 5: Target 5A and 5B on Reducing Maternal Mortality and Achieving Universal Access to Reproductive Health, Geneva: WHO, 2009.

3. Hogan MC et al., Maternal mortality for 181 countries, 1980-2008: a systematic analysis of progress towards Millennium Development Goal 5, Lancet, 2010, 375(9726):1609-1623.

4. Konaté MK, Djibo A and Djiré M, The Impact of Family Planning on the Lives of New Contraceptive Users in Bamako, Research Triangle Park, NC, USA: Centre d'Etudes et de Recherche sur la Population pour le Développement and Family Health International, 1998.

5. Castle $S$ et al., A qualitative study of clandestine contraceptive use in urban Mali, Studies in Family Planning, 1999, 30(3):231-248.

6. Pulerwitz J, Gortmaker SL and DeJong W, Measuring sexual relationship power in HIV/STD research, Sex Roles, 2000, 42(7/8):637-660.

7. Adamu YM and Salihu HM, Barriers to the use of antenatal and obstetric care services in rural Kano, Nigeria, Journal of Obstetrics $\mathcal{E}$ Gynaecology, 2002, 22(6):600-603.

8. Gage AJ, Barriers to the utilization of maternal health care in rural Mali, Social Science \& Medicine, 2007, 65(8):1666-1682.

9. Chapagain M, Conjugal power relations and couples' participation in reproductive health decision-making: exploring the links in Nepal, Gender, Technology and Development, 2006, 10(2):159-189.

10. Ying $\mathrm{C}$, Li Y and Hui H, The impact of husbands' gender equity awareness on wives' reproductive health in rural areas of China, Obstetrical \& Gynecological Survey, 2011, 66(2):103-108.

11. United Nations Population Fund (UNFPA) and EngenderHealth, Obstetric Fistula Needs Assessment Report: Findings from Nine African Countries, New York: UNFPA and EngenderHealth, 2003.

12. Mumtaz Z and Salway SM, Gender, pregnancy and the uptake of antenatal care services in Pakistan, Sociology of Health $\&$ Illness, 2007, 29(1):1-26

13. Syed U et al., Care-seeking practices in South Asia: using formative research to design program interventions to save newborn lives, Journal of Perinatology, 2008, 28(Suppl. 2):S9-S13.

14. AbouZahr C and Wardlaw T, Antenatal Care in Developing Countries: Promises, Achievements, and Missed Opportunities: An Analysis of Trends, Levels and Differentials, 1990-2001, Geneva: WHO and United Nations Children's Fund, 2003.

15. van den Broek NR et al., Reproductive health in rural Malawi: a population-based survey, British Journal of Obstetrics and Gynaecology, 2003, 110(10):902-908

16. WHO, Making Pregnancy Safe: The Critical Role of the Skilled Attendant: A Joint Statement by WHO, ICM and FIGO, Geneva: WHO, 2004.

17. Singh $\mathrm{S}$ et al., Adding It Up: The Costs and Benefits of Investing in Family Planning and Maternal and Newborn Health, New York: Guttmacher Institute and UNFPA, 2009.

18. Lincetto $\mathrm{O}$ et al., Antenatal Care, in: Lawn J and Kerber K, eds., Opportunities for Africa's Newborns: Practical Data, Policy and Programmatic Support for Newborn Care in Africa, Cape Town, South Africa: WHO, 2006, pp. 51-62

19. WHO, WHO Technical Consultation on Postpartum and Postnatal Care, Geneva: WHO, 2010.

20. Gabrysch S et al., The influence of distance and level of care on 
delivery place in rural Zambia: a study of linked national data in a geographic information system, PLoS Medicine, 2011, 8(1):e1000394.

21. Buor D and Bream K, An analysis of the determinants of maternal mortality in Sub-Saharan Africa, Journal of Women's Health, 2004, 13(8):926-938.

22. Nabukera SK et al., Use of postpartum health services in rural Uganda: knowledge, attitudes, and barriers, Journal of Community Health, 2006, 31(2):84-93.

23. Magadi MA, Madise NJ and Rodrigues RN, Frequency and timing of antenatal care in Kenya: explaining the variations between women of different communities, Social Science \& Medicine, 2000, 51(4):551-561.

24. Stephenson R et al., Contextual influences on modern contraceptive use in Sub-Saharan Africa, American Journal of Public Health, 2007, 97(7):1233-1240.

25. Babalola S and Fatusi A, Determinants of use of maternal health services in Nigeria-looking beyond individual and household factors, BMC Pregnancy and Childbirth, 2009, 9, 43.

26. World Bank, World Development Report 2012: Gender Equality and Development, Washington, DC: International Bank for Reconstruction and Development and World Bank, 2011.

27. Jensen $\mathrm{R}$ and Thornton R, Early female marriage in the developing world, Gender and Development, 2003, 11(2):9-19.

28. Boye AK et al., Marriage law and practice in the Sahel, Studies in Family Planning, 1991, 22(6):343-349.

29. Bankole A and Singh S, Couples' fertility and contraceptive decision-making in developing countries: hearing the man's voice, International Family Planning Perspectives, 1998, 24(1):15-24.

30. Beegle K, Frankenberg E and Thomas D, Bargaining power within couples and use of prenatal and delivery care in Indonesia, Studies in Family Planning, 2001, 32(2):130-146.

31. Blanc AK, The effect of power in sexual relationships on sexual and reproductive health: an examination of the evidence, Studies in Family Planning, 2001, 32(3):189-213.

32. Riley NE, Gender, power, and population change, Population Bulletin, 1997, 52(1):1-48.

33. The Prevention of Maternal Mortality Network, Barriers to treatment of obstetric emergencies in rural communities of West Africa, Studies in Family Planning, 1992, 23(5):279-291.

34. Bloom SS, Wypij D and Das Gupta M, Dimensions of women's autonomy and the influence on maternal health care utilization in a north Indian city, Demography, 2001, 38(1):67-78.

35. Amnesty International, Giving Life, Risking Death: Time for Action to Reduce Maternal Mortality in Burkina Faso, London: Amnesty International, 2010.

36. Agha S and Carton TW, Determinants of institutional delivery in rural Jhang, Pakistan, International Journal for Equity in Health, 2011 , 10.1186/1475-9276-10-31, accessed Feb. 12, 2012.

37. DeRose LF and Ezeh AC, Decision-making patterns and contraceptive use: evidence from Uganda, Population Research and Policy Review, 2010, 29(3):423-439.

38. Hindin MJ and Muntifering CJ, Women's autonomy and timing of most recent sexual intercourse in Sub-Saharan Africa: a multicountry analysis, Journal of Sex Research, 2011, 48(6):511-519.

39. Pulerwitz J and Barker G, Measuring attitudes toward gender norms among young men in Brazil, development and psychometric evaluation of the GEM scale, Men and Masculinities, 2008, 10(3):322-338.

40. Cui Y et al., Effect of married women's beliefs about gender equity on their use of prenatal and delivery care in rural China, International Journal of Gynaecology \& Obstetrics, 2010, 111(2):148-151.

41. Boer $\mathrm{H}$ and Mashamba MT, Gender power imbalance and differential psychosocial correlates of intended condom use among male and female adolescents from Venda, South Africa, British Journal of Health Psychology, 2007, 12(Pt. 1):51-63.

42. Mason KO and Smith HL, Husbands' versus wives' fertility goals and use of contraception: the influence of gender context in five Asian countries, Demography, 2000, 37(3):299-311.

43. Kadir MM et al., Do mothers-in-law matter? Family dynamics and fertility decision-making in urban squatter settlements of Karachi, Pakistan, Journal of Biosocial Science, 2003, 35(4):545-558.

44. Pettifor AE et al., Sexual power and HIV risk, South Africa, Emerging Infectious Diseases, 2004, 10(11):1996-2004

45. Haque SE et al., Reproductive health care utilization among young mothers in Bangladesh: Does autonomy matter? Women's Health Issues, 2012, 22(2):e171-e180.

46. Becker S, Fonseca-Becker F and Schenck-Yglesias C, Husbands' and wives' reports of women's decision-making power in Western Guatemala and their effects on preventive health behaviors, Social Science \& Medicine, 2006, 62(9):2313-2326.

47. Simkhada B, Porter MA and van Teijlingen ER, The role of mothers-in-law in antenatal care decision-making in Nepal: a qualitative study, BMC Pregnancy and Childbirth, 2010, 10.1186/1471-2393-1034, accessed June 12, 2012

48. World Bank, Reproductive Health at a Glance: Mali, Washington, DC: World Bank, 2011.

49. U.S. Department of State, 2010 Human Rights Report: Mali, Washington, DC: U.S. Department of State, 2011.

50. Organisation for Economic Co-operation and Development Centre, Social institutions and gender index: Mali, 2012, <http:// genderindex.org/country/mali>, accessed Mar. 21, 2012

51. Cellule de Planification et de Statistique du Ministère de la Santé (CPS), Direction Nationale de la Statistique et de l'Informatique du Ministère de l'Économie, de l'Industrie et du Commerce (DNSI), Enquête Démographique et de Santé du Mali 2006, Calverton, MD, USA: CPS/DNSI and Macro International, 2007

52. Kaggwa EB, Diop N and Storey JD, The role of individual and community normative factors: a multilevel analysis of contraceptive use among women in union in Mali, International Family Planning Perspectives, 2008, 34(2):79-88

53. Yoder PS, Guèye M and Konaté M, The Use of Family Planning Methods in Mali: The How and Why of Taking Action, Calverton, MD, USA: ICF Macro, 2011.

54. Al-Krenawi A, Women of polygamous marriages in primary health care centers, Contemporary Family Therapy, 1999, 21(3):417-430.

55. Gibson MA and Mace R, Polygyny, reproductive success and child health in rural Ethiopia: why marry a married man? Journal of Biosocial Science, 2007, 39(2):287-300.

56. Bove R and Valeggia C, Polygyny and women's health in SubSaharan Africa, Social Science \& Medicine, 2009, 68(1):21-29.

57. DiClemente RJ et al., Efficacy of an HIV prevention intervention for African American adolescent girls: a randomized controlled trial, Journal of the American Medical Association, 2004, 292(2):171-179.

58. Family Care International (FCI), Care-Seeking During Pregnancy, Delivery, and the Postpartum Period: A Study in Homabay and Migori Districts, Kenya, New York: FCI, 2003.

59. Kruk ME et al., Women's preferences for place of delivery in rural Tanzania: a population-based discrete choice experiment, American Journal of Public Health, 2009, 99(9):1666-1672.

60. Bowser D and Hill K, Exploring Evidence for Disrespect and Abuse in Facility-Based Childbirth: Report of a Landscape Analysis, Washington, DC: USAID, 2010

61. van Eijk AM et al., Use of antenatal services and delivery care among women in rural western Kenya: a community based survey, Reproductive Health, 2006, 10.1186/1742-4755-3-2, accessed Mar. 17, 2012

62. Overbosch GB et al. Determinants of antenatal care use in Ghana, Journal of African Economies, 2004, 13(2):277-301.

63. Bankole A, Desired fertility and fertility behaviour among the Yoruba of Nigeria: a study of couple preferences and subsequent fertility, Population Studies, 1995, 49(2):317-328.

64. Char A, Saavala M and Kulmala T, Influence of mothers-in-law on young couples' family planning decisions in rural India, Reproductive Health Matters, 2010, 18(35):154-162. 
APPENDIX TABLE 1. Proportion of variance explained by the first principal component and Cronbach's alpha reliability coefficient, by respondent type

\begin{tabular}{|c|c|c|c|c|c|c|}
\hline & \multicolumn{2}{|l|}{ Women } & \multicolumn{2}{|l|}{ Husbands } & \multicolumn{2}{|c|}{ Mothers-in-law } \\
\hline & $\begin{array}{l}\text { Proportion } \\
\text { of variance }\end{array}$ & $\begin{array}{l}\text { Cronbach's } \\
\text { alpha }\end{array}$ & $\begin{array}{l}\text { Proportion } \\
\text { of variance }\end{array}$ & $\begin{array}{l}\text { Cronbach's } \\
\text { alpha }\end{array}$ & $\begin{array}{l}\text { Proportion } \\
\text { of variance }\end{array}$ & $\begin{array}{l}\text { Cronbach's } \\
\text { alpha }\end{array}$ \\
\hline Traditional and cultural practices & 0.266 & 0.352 & 0.261 & 0.245 & 0.241 & 0.323 \\
\hline Value of women & 0.362 & 0.608 & 0.298 & 0.524 & 0.346 & 0.597 \\
\hline Marital conduct and responsibility & 0.278 & 0.294 & 0.286 & 0.301 & 0.267 & 0.335 \\
\hline Attitudes toward the health facility & 0.317 & 0.672 & 0.299 & 0.681 & 0.313 & 0.706 \\
\hline Perceived efficacy of the index woman & 0.548 & 0.582 & 0.451 & 0.373 & 0.501 & 0.501 \\
\hline Difference in perceived decision-making & & & & & & \\
\hline power between husband and wife & 0.318 & 0.397 & 0.307 & 0.358 & 0.301 & 0.425 \\
\hline Perceived household trust and respect + & 0.515 & 0.762 & na & na & na & na \\
\hline
\end{tabular}

\section{RESUMEN}

Contexto: La evidencia proveniente de diversos entornos sugiere que las mujeres tienen a menudo un control limitado sobre sus propias decisiones de salud reproductiva. Con el fin de aumentar la aceptación de servicios y conductas de prevención, es importante comprender cómo las dinámicas de poder al interior de la familia y las actitudes de las mujeres, de sus esposos y de sus suegras están asociadas con las prácticas de salud materna.

Métodos: En 317 hogares ubicados en dos distritos rurales de Mali central, las mujeres que habian dado a luz el año anterior, sus esposos y sus suegras contestaron a una encuesta para medir sus actitudes en relación a los conceptos de género, poder y salud. Se condujeron análisis de regresión logística bivariada y multivariada con el fin de identificar asociaciones con cuatro resultados de salud materna: frecuencia de la atención prenatal, oportunidad de la atención prenatal, parto institucional y atención postnatal.

Resultados: En los análisis multivariados, las preferencias y opiniones de las suegras fueron asociadas con las conductas relacionadas con la salud materna de sus nueras. Las propias percepciones de las mujeres acerca de su autoeficacia, el valor de las mujeres en la sociedad y la calidad de los servicios en las instituciones locales de salud también se asociaron independientemente con sus prácticas de prevención y de búsqueda de conductas saludables. Las preferencias y opiniones de los esposos no fueron asociadas con ningún resultado.

Conclusiones: Las intervenciones que se centran en las mujeres o parejas pueden ser insuficientes a la hora de fomentar la salud reproductiva de las mujeres en sociedades patriarcales tales como Mali. Los futuros esfuerzos programáticos y de investigación deben tener en cuenta las normas de género y considerar la influencia de otros miembros de la familia, tales como las suegras.

\section{RÉSUMÉ}

Contexte: Les données relevées dans différents contextes laissent entendre que les femmes ne disposent souvent que d'un contrôle limité sur les décisions relatives à leur propre santé reproductive. Pour accroître l'adoption de services et comportements préventifs, il importe de comprendre l'association entre, d'une part, la dynamique du pouvoir intrafamilial et les attitudes des femmes, des maris et des belles-mères et, d'autre part, les pratiques de santé maternelle.

Méthodes: Dans 317 ménages de deux districts ruraux du Mali central, les femmes qui avaient accouché durant l'année précédente et les maris et belles-mères de ces femmes ont été invités, chacun et chacune, à répondre à un questionnaire d'évaluation de leurs attitudes à l'égard des notions de genre, de pouvoir et de santé. Des analyses de régression logistique biet multivariées ont été réalisées pour identifier les associations avec quatre issues de santé maternelle: fréquence des soins prénatals, moment des soins prénatals, accouchement en milieu institutionnel et soins postnatals.

Résultats: Dans les analyses multivariées, les préférences et les opinions des belles-mères sont associées aux comportements de santé maternelle des belles-filles. Les perceptions personnelles des femmes concernant leur auto-efficacité, la valeur des femmes dans la société et la qualité des services au niveau de l'établissement de santé local se révèlent aussi indépendamment associées à leurs pratiques préventives et de recherche de la santé. Les préférences et opinions des maris ne sont associées à aucune issue.

Conclusions: Les interventions axées sur les femmes ou les couples ne suffisent peut-être pas à promouvoir la santé reproductive des femmes dans les sociétés patriarcales telles que celle du Mali. La recherche et les efforts programmatiques futurs devront prendre en considération les normes de genre et l'influence d'autres membres de la famille, notamment les belles-mères.

\section{Acknowledgments}

The authors acknowledge the contributions of CARE Mali, particularly the Projet Espoir team, for their roles in data collection and project implementation. They also acknowledge Benjamin Schwartz, the director of the Health Equity Unit in CARE USA, for reviewing and technical support. Finally, Henriette Bulambo and Elizabeth Swedo, interns from Emory University, provided support and quality assurance throughout data collection. This research was supported by the Tides Foundation, with funds from Google. The authors declare no potential conflicts of interest with respect to the authorship or publication of this article.

Author contact: darcy.white@emory.edu 